Original Article

\title{
Sleep disorders and depression due to menopausal symptoms in middle-aged Korean females
}

\author{
KIm Jin, PhD ${ }^{1)}$, Cha Nam Hyun, PhD $\left.{ }^{2}\right)^{*}$ \\ 1) Department of Nursing, Jeonbuk Science College, Republic of Korea \\ 2) Department of Nursing, Andong National University: 1375 Gyeongdong-ro Andong-si \\ Gyeongsangbuk-do, Andong, Gyeongsangbuk-do 36722, Republic of Korea
}

\begin{abstract}
Purpose] The purpose of this study was to identify the differences in the incidence of sleep disorders and depression in postmenopausal middle-aged females in South Korea. [Participants and Methods] This study was a cross-sectional study. A total of 87 middle-aged females between the ages of 40 and 60 years were selected through convenience sampling. The data were collected with a self-reported questionnaire from May 1 to May 29, 2017. [Results] The mean menopause score of the study was 5.37. The menopause symptoms indicated significant differences in sexual life. The association between the incidence of menopausal symptoms and sleep disorders and depression scores based on a scale of 1 to 10 was analyzed. Menopausal symptoms strongly affected sleep and depression in middle-aged females. [Conclusion] The findings of this study may be useful in understanding depression and sleep disorders in middle-aged females and for developing more specific programs for depression and sleep disorders. Management strategies are also needed.

Key words: Depression, Menopause, Females
\end{abstract}

(This article was submitted Feb. 25, 2021, and was accepted Apr. 7, 2021)

\section{INTRODUCTION}

Females manifest with irregular menstrual cycles or the complete cessation of menstruation around age 40 to 60 years and experience a decline in health as they enter middle age ${ }^{1)}$. Menopause can lead to physical, mental, and sexual effects, such as facial flushing, irregular menstrual cycles, psychological changes, sexual dysfunction, osteoporosis, and the increased risk of cardiovascular disease ${ }^{2)}$. Also, the frequency and intensity of menopausal symptoms vary depending upon the culture and the menopausal circumstances and may seriously affect or reduce the quality of life of women ${ }^{3)}$. Thus, although several methods such as diet, psychotherapy ${ }^{4)}$, hormone therapy, physical activity, replacement therapy, and popular therapy have been used to relieve menopausal symptoms, most middle-aged females consider it a natural event in a woman's life ${ }^{2)}$ and do not treat them ${ }^{4}$.

Middle-aged females experience depression due to the lack of serotonin caused by a decline in estrogen, progesterone, and norepinephrine during menopause, which affects mood, sleep, and appetite ${ }^{5)}$. Also, physical changes and changing social roles induce psychological anxiety in middle-aged females. Failure to respond adequately to these physiological changes results in psychological anxiety and depression. Depression is a menopausal symptom that frequently refers to various events in the life cycle of a middle-aged woman and is more common in females than in men ${ }^{6}$. Therefore, depression is a psychological disorder and is one of the main challenges affecting postmenopausal females ${ }^{7}$.

Depression in middle-aged females is linked to inadequate sleep, causing psychological instability manifesting as a physical problem. Sleep recharges and rejuvenates the body physically and mentally by restoring and stabilizing circulation and biorhythms, which affect one's well-being and quality of life ${ }^{8)}$. Sleep disorders are especially likely to cause depression in

*Corresponding author. Cha Nam Hyun (E-mail: yeoreo@daum.net)

(C2021 The Society of Physical Therapy Science. Published by IPEC Inc.

(c) $(-)$ This is an open-access article distributed under the terms of the Creative Commons Attribution Non-Commercial No DerivaCC BY NC ND tives (by-nc-nd) License. (CC-BY-NC-ND 4.0: https://creativecommons.org/licenses/by-nc-nd/4.0/) 
females $^{9}$. Therefore, depression and sleep disorders in middle-aged females can only have a negative impact on their health and the alleviation of menopausal symptoms is essential to improving their quality of life.

Most previous studies conducted in middle-aged females were technical studies investigating depression and sleep disorders, with few studies exploring subjective measures. Middle-aged females develop physical, psychological, and genital problems due to menopause. In this study, it is important to identify sleep problems ${ }^{10)}$ and depression ${ }^{11)}$ as well as sexual life effects as a result of menopausal symptoms, and provide a subjective score for depression and sleep disorders.

The purpose of this study was to identify the menopausal symptoms, the differences between menstrual and birth-related variables, and the differences between sleep disorders and depression in menopausal symptoms.

\section{PARTICIPANTS AND METHODS}

This study was a cross-sectional study. This study was approved by the Institutional Bioethics Committee of the Andong National University. The participants agreed to participate in the study and signed a consent form after hearing sufficient explanations of the purpose, format, and objectives of the research structure, including ethical considerations related to the protection of the study participants. The participants were advised that they could withdraw at any time for any reason. The participants were 87 middle-aged females at two local community centers in S city in South Korea who were capable of responding to the questions. The participants were 40-60-year-old women selected through convenience sampling. The data collection period was implemented for one month from May 1 to May 29, 2017. The study measured general characteristics and menopausal symptoms, as well as sleep disorders and depression scores based on a numeric rating scale ranging from 1 to 10 . The scale scores ranged from one point for "not at all" to 10 points for "very much". Data analysis was performed using the SPS/WIN 23.0 statistical program (IBM Corp., 2015; Armonk, NY, USA). The general characteristics of the participants were analyzed by frequency, percentage, average, and standard deviation using technical statistics. A $\chi^{2}$-test was used to test the differences in the dependent variables based on general characteristics. The analysis of variance (ANOVA) test and the Scheffe post-hoc test were used to analyze the differences between the dependent variables.

\section{RESULTS}

In this study, females in their $50 \mathrm{~s}$ accounted for $57.6 \%$ of the respondents, those in their $40 \mathrm{~s}$ constituted $30.5 \%$, and those in their $60 \mathrm{~s}$ and older comprised the remaining $11.9 \%$. Females who graduated from high school accounted for $62.7 \%$ and those who graduated from university or higher constituted $37.3 \%$. More than half of the participants were religious. The proportion of females experiencing regular menstruation was $25.3 \% ; 59.8 \%$ menstruated naturally, and $12.6 \%$ menstruated through gynecological surgery. The mean \pm SD age at the first of menstrual period was $21 \pm 2.7$ years, the number of pregnancies was $3.08 \pm 1.4$, and there was an average of $2.11 \pm 0.8$ births, $2.09 \pm 0.8$ children, and $1.10 \pm 1.1$ stillbirths (Table 1).

Based on a numeric rating scale of 1 to 10 points, the average symptom score was $5.37 \pm 1.9$ points. Based on the classification of menopausal symptoms, $15.1 \%$ scored $1-3$ points, $57.0 \%$ scored $4-6$ points, and $27.9 \%$ scored $7-10$ points (Table 2).

Table 1. Demographic and menopausal factors $(\mathrm{N}=87)$

\begin{tabular}{|c|c|c|c|c|}
\hline Variables & Categories & $\mathrm{n}$ & $\%$ & Mean \pm SD \\
\hline \multirow{3}{*}{ Age (years) } & $40-49$ & 27 & 30.5 & \\
\hline & $50-59$ & 50 & 57.6 & \\
\hline & $\geq 60$ & 10 & 11.9 & \\
\hline \multirow{2}{*}{ Education level } & $\leq$ High school & 55 & 62.7 & \\
\hline & $\geq$ University & 32 & 37.3 & \\
\hline \multirow{2}{*}{ Religion } & Yes & 50 & 57.5 & \\
\hline & No & 37 & 42.5 & \\
\hline \multirow{4}{*}{ Menstrual condition } & Regular & 22 & 25.3 & \\
\hline & Irregular & 2 & 2.3 & \\
\hline & Loss of natural menstruation & 52 & 59.8 & \\
\hline & No menstruation due to gynecological surgery & 11 & 12.6 & \\
\hline First menstrual period (age) & & & & $21 \pm 2.7$ \\
\hline Number of children & & & & $2.09 \pm 0.8$ \\
\hline Number of pregnancies & & & & $3.08 \pm 1.4$ \\
\hline Number of deliveries & & & & $2.11 \pm 0.8$ \\
\hline Number of stillbirths & & & & $1.10 \pm 1.1$ \\
\hline
\end{tabular}


After classifying the menopausal symptoms into three categories, mild, moderate, and severe, we determined the general characteristics and differences, and found that the differences in sexual life were statistically significant $(p<0.05)$, i.e., the group that experienced minor menopausal symptoms was mostly satisfied with their sexual life (69.2\%), the group with moderate menopausal symptoms was more likely to have a moderate sexual life $(60.0 \%)$, and the group with severe menopausal symptoms was more likely to have a moderate or unsatisfied with their sexual life (50.0\% or 33.3\%). The most common responses were that the health conditions were moderate but were not statistically significant. Smoking did not yield statistically significant results because none of the participants smoked. Drinking and exercise were also not significantly different (Table 3).

No variables were significantly different between the menopausal symptom severity groups (Table 4).

The analysis of sleep disorders and depression in the study participants rated on a numeric rating scale from 1 to 10 suggested that menopausal symptoms and sleep disorder $(p<0.01)$ and depression $(p<0.05)$ scores were statistically significant. The mean sleep disorder score of those who complained of severe menopause was 6.42 points (Table 5).

Table 2. Intensity/severity among females with menopausal symptoms $(\mathrm{N}=87)$

\begin{tabular}{llccc}
\hline Variables & Intensity (range) & $\mathrm{N}$ & $\%$ & Mean \pm SD \\
\hline Menopausal symptoms & Mild (1-3) & 13 & 15.1 & $5.37 \pm 1.9$ \\
& Moderate (4-6) & 50 & 57.0 & \\
& Severe (7-10) & 24 & 27.9 & \\
\hline
\end{tabular}

Table 3. Differences in general characteristics according to menopausal symptom severity $(\mathrm{N}=87)$

\begin{tabular}{|c|c|c|c|c|c|c|}
\hline \multicolumn{2}{|c|}{ Variables } & $\begin{array}{c}\text { Mild } \\
(\mathrm{n}=13)\end{array}$ & $\begin{array}{c}\text { Moderate } \\
(\mathrm{n}=50)\end{array}$ & $\begin{array}{l}\text { Severe } \\
(\mathrm{n}=24)\end{array}$ & \multirow[t]{3}{*}{$\chi^{2}$} & \multirow[t]{2}{*}{$\mathrm{p}$} \\
\hline \multirow{4}{*}{ Sexual life } & & & & & & \\
\hline & Satisfactory & $9(69.2)$ & $8(16.0)$ & $4(16.7)$ & & \multirow{3}{*}{$0.025^{*}$} \\
\hline & Ordinary & $4(30.8)$ & $30(60.0)$ & $12(50.0)$ & \multirow[t]{2}{*}{11.138} & \\
\hline & Unsatisfactory & $0(0.0)$ & $12(24.0)$ & $8(33.3)$ & & \\
\hline \multirow[t]{3}{*}{ Health state } & Good & $2(15.4)$ & $6(12.0)$ & $4(16.7)$ & \multirow{3}{*}{4.228} & \multirow{3}{*}{0.376} \\
\hline & Ordinary & $8(61.5)$ & $30(60.0)$ & $12(50.0)$ & & \\
\hline & $\mathrm{Bad}$ & $3(23.1)$ & $14(28.0)$ & $8(33.3)$ & & \\
\hline \multirow[t]{2}{*}{ Disease } & Yes & $5(38.5)$ & $38(76.0)$ & $16(66.7)$ & \multirow{2}{*}{4.349} & \multirow{2}{*}{0.114} \\
\hline & No & $8(61.5)$ & $12(24.0)$ & $8(33.3)$ & & \\
\hline \multirow[t]{2}{*}{ Smoking } & Yes & $0(0.0)$ & $0(0.0)$ & $0(0.0)$ & \multirow{2}{*}{ - } & \multirow{2}{*}{-} \\
\hline & No & $13(100.0)$ & $50(100.0)$ & $24(100.0)$ & & \\
\hline \multirow[t]{2}{*}{ Drinking } & Yes & $13(100.0)$ & $44(88.0)$ & $21(87.5)$ & \multirow{2}{*}{1.791} & \multirow{2}{*}{0.408} \\
\hline & No & $0(0.0)$ & $6(12.0)$ & $3(12.5)$ & & \\
\hline \multirow[t]{2}{*}{ Exercise } & Yes & $3(23.1)$ & $19(38.0)$ & $9(37.5)$ & \multirow{2}{*}{1.129} & \multirow{2}{*}{0.569} \\
\hline & No & $10(76.9)$ & $31(62.0)$ & $15(52.5)$ & & \\
\hline
\end{tabular}

$* \mathrm{p}<0.05$.

Table 4. Differences in menstruation and birth-related variables based on menopausal symptom severity (N=87)

\begin{tabular}{lcccc}
\hline \multicolumn{1}{c}{ Variables } & $\begin{array}{c}\text { Mild } \\
(\mathrm{n}=13)\end{array}$ & $\begin{array}{c}\text { Moderate } \\
(\mathrm{n}=50)\end{array}$ & $\begin{array}{c}\text { Severe } \\
(\mathrm{n}=24)\end{array}$ & $\mathrm{p}$ \\
\cline { 2 - 4 } & Mean $\pm \mathrm{SD}$ & Mean $\pm \mathrm{SD}$ & Mean $\pm \mathrm{SD}$ & \\
\hline First menstrual period (age) & $15.38 \pm 1.4$ & $14.80 \pm 2.7$ & $14.92 \pm 3.2$ & 0.783 \\
Number of children & $2.00 \pm 0.4$ & $2.12 \pm 0.8$ & $2.08 \pm 0.9$ & 0.880 \\
Number of pregnancies & $3.15 \pm 1.3$ & $2.98 \pm 1.3$ & $3.21 \pm 1.6$ & 0.785 \\
Number of deliveries & $2.15 \pm 0.6$ & $2.14 \pm 0.8$ & $2.04 \pm 0.9$ & 0.863 \\
Number of stillbirths & $1.00 \pm 1.4$ & $0.98 \pm 0.9$ & $1.38 \pm 1.4$ & 0.361 \\
\hline
\end{tabular}


Table 5. Differences in sleeping disorders and depression based on menopausal symptom severity $(\mathrm{N}=87)$

\begin{tabular}{lcccc}
\hline \multirow{2}{*}{ Variables } & $\begin{array}{c}\text { Mild } \\
(\mathrm{n}=13)\end{array}$ & $\begin{array}{c}\text { Moderate } \\
(\mathrm{n}=50)\end{array}$ & $\begin{array}{c}\text { Severe } \\
(\mathrm{n}=24)\end{array}$ & $\mathrm{p}$ \\
\cline { 2 - 4 } & Mean $\pm \mathrm{SD}$ & Mean $\pm \mathrm{SD}$ & Mean $\pm \mathrm{SD}$ & \\
\hline Sleep disorder (score)* & $4.69 \pm 1.8 \mathrm{a}$ & $4.92 \pm 1.9 \mathrm{~b}$ & $6.42 \pm 1.9 \mathrm{ab}$ & $0.004^{* *}$ \\
Depression (score)* & $3.32 \pm 1.9 \mathrm{a}$ & $4.12 \pm 2.1 \mathrm{~b}$ & $4.92 \pm 2.2 \mathrm{ab}$ & $0.045^{*}$ \\
\hline
\end{tabular}

*Scheffe test: ${ }^{*} \mathrm{p}<0.05, * * \mathrm{p}<0.01 . \mathrm{a}<\mathrm{b}<\mathrm{ab}$.

\section{DISCUSSION}

This study was conducted to identify the differences in the incidence of sleep disorders and depression due to menstrual symptoms in middle-aged females living in South Korea.

In this study, based on a numeric rating scale from 1 to 10 , the menopausal symptoms were an average of $5.37 \pm 1.9$, consistent with the score of 5.03 reported by Park et al. ${ }^{12)}$ who calculated the target menopausal symptom scores using the Menopause Symptom Index (MENSI). However, by changing the MENSI tool to a perfect score of 10, the previous study on menopausal symptoms conducted by Lee and Kang ${ }^{13)}$ differed by 8.6 points ${ }^{13}$, and by 3.8 points in the study by Kim and $\mathrm{Kim}^{14)}$. However, another study reported that approximately $50 \%$ of women or more experienced menopausal symptoms before and after menopause ${ }^{15)}$, consistent with the results of this study. Therefore, symptom management measures are needed. Based on the analysis of general characteristics and differences according to the degree of menopausal symptoms, sexual life was statistically significant. The group reporting minor menopausal symptoms was mostly satisfied with their sexual life, the group with moderate symptoms was more likely to be satisfied, and the group that showed severe menopause symptoms was more likely to report moderate sexuality or dissatisfaction with their sexual life. These findings supported the study by Park et al. ${ }^{12}$, which suggested that menopausal symptoms were related to sexual life. Middle-aged females in menopause experience sexual dysfunction due to vaginal dryness caused by hormonal changes ${ }^{2}$. Sexual conflict is associated with marital conflict and sexual satisfaction has a great impact on the quality of life ${ }^{15}$, suggesting the need for education, physical support, and measures to maintain a satisfying sexual life in middle-aged females. The evaluation of sleep disorders and depression on a scale of 1 to 10 showed a statistically significant association between menopause and depression, i.e., sleep disorders and depression in the participants with severe menopausal symptoms were higher than in those with mild symptoms. This finding confirmed the correlations between menopausal symptoms and sleep disorders and depression ${ }^{5,16)}$. While menopausal symptoms suggest biological decline due to age, the resulting discomfort in daily life, as well as physical and psychological distress have a large impact on the quality of life and require treatment and management of symptoms. Increased physical activity, positive mind control, and social participation are needed to alleviate sleep disorders and depression. Educational programs are needed to help females develop and cope with menopause problems and provide space and programs for their activities in society.

In this study, the participants' average weight $(\mathrm{kg})$, height $(\mathrm{cm})$, and body mass index $(\mathrm{BMI})$ were not measured due to the low association because it is a conceptual research between menopausal symptoms, sleep disorders, and depression, and it is a study that wants to see the difference.

The results of this study highlight the need for developing and applying a physical therapy program to help women cope with menopausal symptoms (mild, moderate, and severe).

\section{Funding and Conflict of interest}

The authors received no specific funding for this work, and that the authors have no conflicts of interest directly relevant to the content of this article.

\section{REFERENCES}

1) Rymer J, Morris EP: Extracts from “clinical evidence": menopausal symptoms. BMJ, 2000, 321: 1516-1519. [Medline] [CrossRef]

2) Falahzadeh H, Tafti AD, Tafti MD, et al.: Factors affecting quality of life after menopause in females. J Shahid Sadoughi Univ Med Sci Health Serv, 2011, 18: $552-558$.

3) Chuni N, Sreeramareddy CT: Frequency of symptoms, determinants of severe symptoms, validity of and cut-off score for Menopause Rating Scale (MRS) as a screening tool: a cross-sectional survey among midlife Nepalese females. BMC Femaless Health, 2011, 11: 1-9.

4) Hyun MS: Use of complementary and alternative therapy related to menopausal status and climacteric symptoms in middle-aged females. Unpublished master's thesis, Kyonggi University. Suwon, 2018.

5) Llaneza P, García-Portilla MP, Llaneza-Suárez D, et al.: Depressive disorders and the menopause transition. Maturitas, 2012, 71: 120-130. [Medline] [CrossRef] 
6) Freeman EW: Depression in the menopause transition: risks in the changing hormone milieu as observed in the general population. Womens Midlife Health, 2015, 1: 2. [Medline] [CrossRef]

7) Zang H, He L, Chen Y, et al.: The association of depression status with menopause symptoms among rural midlife women in China. Afr Health Sci, 2016, 16: 97-104. [Medline] [CrossRef]

8) Paik YN, Song MS: Sleep disturbing factors and the relative significance in sleep of hospitalized elderly patients. J Korean Gerontol Nurs, 2000 , 2: 35-47.

9) Armitage R, Hoffmann RF: Sleep EEG, depression and gender. Sleep Med Rev, 2001, 5: 237-246. [Medline] [CrossRef]

10) Tasnim S, Haque A, Nazmeen S: Experience of menopause and menopausal transition among middle aged females attending a periurban hospital. Bangladesh J Obstet Gynaecol, 2016, 31: 10-15. [CrossRef]

11) Lee YJ: Gender differences in factors associated with the severity of depression in middle-aged adults: an analysis of 2014 Korean national health and nutrition examination survey. J Korea Convergence Soc, 2018, 9: 549-559.

12) Park YK, Cha NH, Sok SR: Relationships between menopausal syndrome and sleeping of middle-aged women. J Phys Ther Sci, 2015, 27: 2537-2540. [Medline] [CrossRef]

13) Lee KS, Kang GW: A Study on the relationship between climacteric and depressive symptoms in middle aged females in an area. J Korean Clin Health Sci, 2018, 6: 1171-1179.

14) Kim SJ, Kim SY: A study on the relationship of marital intimacy, depression, and menopausal symptoms in middle-aged females. Korean J Females Health Nurs, 2013, 19: 176-187. [CrossRef]

15) Sung MH: Self-reported climacteric symptoms, self concept and depression in middle-aged females. Korean J Adult Nurs, 2002 , 14 : $102-113$.

16) Mohammed SF, Mohammed NS: Effect of menopausal symptoms on psychological problems among middle-aged females. Egypt Nurs J, 2018 , 15: 292-301. [CrossRef] 